\title{
Does smoking impair sleep hygiene?
}

\author{
0 tabagismo prejudica a higiene do sono? \\ Didem Görgün HATTATOĞLU1', Șenay AYDIN², Birsen Pınar YILDIZ1
}

\begin{abstract}
Background: Sleep architecture and sleep hygiene might be disrupted by several pathogenetic mechanisms, and the effect of smoking has not been evaluated. Objective: To investigate the effect of smoking on sleep hygiene behaviors that might be associated with the deterioration of quality-of-life (QoL) parameters. Methods: In a prospective cross-sectional study, smokers $(n=114)$ and nonsmokers $(n=119)$ were included. The Pittsburgh Sleep Quality Index (PSQI), the Epworth Daytime Sleepiness Scale (ESS), the Sleep Hygiene Index (SHI), and the Short Form-36 quality of life scale (SF-36) were applied. Results: We found that none of the components, as well as the PSQI total score were affected in smokers compared with the nonsmoker controls (65.5\% of smokers had poor sleep compared to $62.5 \%$ of nonsmokers). Although smokers tend to get out of bed at different times from day to day and do important work before bedtime (components of the SHI) more often than non-smokers, no significant differences were detected between groups in any component and SHI total score (27.91 \pm 6.72 for smokers and 29.23 \pm 8.0 for non-smokers). ESS, depression and anxiety symptoms, and SHI scores in smokers with poor sleep quality were significantly different compared with smokers that had normal sleep quality. Both PSQI and SHI scores were inversely associated with QoL parameters. Conclusions: Our results suggest that smoking by itself is not associated with poor sleep hygiene or sleep quality. It can be concluded that worse SHI and quality of sleep negatively affect QoL, depression, and anxiety in smokers.
\end{abstract}

Keywords: Sleep Hygiene; Smoking; Sleep Wake Disorders.

\section{RESUMO}

Antecedentes: A arquitetura e a higiene do sono podem ser interrompidas por vários mecanismos patogenéticos, e o efeito do tabagismo ainda não foi avaliado. Objetivo: Investigar o efeito do tabagismo nos comportamentos de higiene do sono que podem estar associados à deterioração dos parâmetros de qualidade de vida (QV). Métodos: Em um estudo transversal prospectivo, foram incluídos fumantes ( $n=114$ ) e não fumantes ( $n=119$ ). Foram aplicados o índice de qualidade do sono de Pittsburgh (Pittsburgh Sleep Quality Index — PSQI), a escala de sonolência diurna de Epworth (ESS), o índice de higiene do sono (Sleep Hygiene Index - SHI) e a escala de qualidade de vida Short Form36 (SF-36). Resultados: Descobrimos que nenhum dos componentes, assim como o escore total do PSQI, foram afetados em fumantes em comparação com os controles não fumantes (65,5\% dos fumantes dormiam mal em comparação com 62,5\% dos não fumantes). Embora os fumantes tendam a sair da cama em horários diferentes do dia a dia e fazer trabalhos importantes antes de dormir (componentes do SHI) com mais frequência do que os não fumantes, não foram detectadas diferenças significativas entre os grupos em qualquer componente

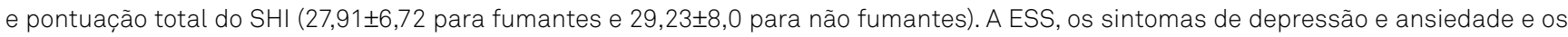
escores SHI em fumantes com má qualidade de sono foram significativamente diferentes em comparação com fumantes com qualidade de sono normal. Os escores do PSQI e SHI foram inversamente associados aos parâmetros de QV. Conclusões: Nossos resultados sugerem que o tabagismo por si só não está associado à má higiene ou qualidade do sono. Pode-se concluir que o pior SHI e a qualidade do sono afetam negativamente a QV, a depressão e a ansiedade em fumantes.

Palavras-chave: Higiene do Sono; Fumar; Transtornos do Sono-Vigília.

\section{INTRODUCTION}

The effects of smoking and related factors on sleep disturbances are not well known, although they may affect the development and course of smoking-related health outcomes. It has been suggested that smoking is a risk factor for the presence of poor sleep patterns ${ }^{1,2,3}$. Sleep hygiene, i.e., behaviors that improve the quality and quantity of sleep, might be an important target for better sleep quality in smokers ${ }^{4}$. Nevertheless, there are insufficient data to show the effect of sleep hygiene on sleep quality and quality of life parameters in smokers.

\footnotetext{
1University of Health Sciences, Yedikule Chest Disease and Surgery Training and Research Hospital, Pulmonology, Istanbul, Turkey. 2University of Health Sciences, Yedikule Chest Disease and Surgery Training and Research Hospital, Neurology, Istanbul, Turkey DGH (D) https://orcid.org/0000-0001-7067-9360; SA (D) https://orcid.org/0000-0003-4460-9056; BPY (D) https://orcid.org/0000-0002-6650-1495 Correspondence: Didem Görgün Hattatoğlu; Email: didem_gorgun @yahoo.com

Conflict of interest: There is no conflict of interest to declare.
}

Authors' contributions: DGH, ȘA: conceived the study and supervised all aspects of its implementation, collaborated in the inception of the study, collected the data, and carried out the analysis of the data; PY: collaborated in the analysis and writing of the manuscript. All authors contributed to the interpretation of the results and the proofreading of the manuscript.

Received on December 08, 2020; Received in its final form on January 07, 2021; Accepted on January 17, 2021. 
We aimed to investigate the effect of smoking on sleep hygiene behaviors. Furthermore, we analyzed associations between poor sleep hygiene and sleep quality in smokers as well as the effects on quality of life parameters.

\section{METHODS}

\section{Study population}

A prospective cross-sectional study was conducted between January and June 2018 in a tertiary care hospital. A total of 114 smokers (55 males and 59 females) and 119 non-smokers (44 males and 75 females) were included in the study.

All participants completed a background questionnaire that included demographic information such as age, job, body mass index (BMI), education time, smoking status, pack/ year of smoking, Fagerstrom nicotine-dependent score, alcohol use, and comorbidities; the latter was scored using the Charlson Comorbidity Index (CI). Participants who smoked $<100$ cigarettes in their entire life and who had quitted smoking at least two years before were classified as non-smokers, those who had smoked $\geq 100$ cigarettes in their entire life and were currently smoking every day or some days for at least one year were classified as smokers ${ }^{5}$.

The exclusion criteria were age $<18$ years, current use of anti-depressive and hypnotic drugs, major systemic illness, malignancy, and pregnancy. Participants who had sleep disorders such as obstructive sleep apnea syndrome and restless leg syndrome were evaluated clinically using questionnaires developed for these disorders and excluded from the study.

Our study was approved by the local ethics committee and all participants gave written informed consent.

\section{Assessments}

The Fagerstrom Test for Nicotine Dependence-SLT (FTND-ST) is a 6-item questionnaire for assessing the dependence of oral tobacco use. A score of 5 or more indicates a significant dependence, while a score of 4 or less shows a low to moderate dependence ${ }^{6}$.

Our primary outcome was sleep hygiene changes in smokers. The Sleep Hygiene Index (SHI) is a 13-item selfadministered index ${ }^{7}$. Participants were asked to indicate how frequently they repeat specific behaviors (always $=5$, frequently $=4$, sometimes $=3$, rarely $=2$, never $=1$ ). The total possible score ranges between 13 and 65, with higher scores indicating poorer sleep hygiene ${ }^{8}$.

Sleep quality was measured using the Pittsburgh Sleep Quality Index (PSQI). This questionnaire consists of 19 selfadministered questions, divided into seven components: (PS1) subjective sleep quality; (PS2) sleep latency; (PS3) sleep duration as the ratio between time slept and time in bed, not necessarily sleeping; (PS4) habitual sleep efficiency; (PS5) sleep disturbances (presence of situations that compromise hours of sleep); (PS6) use of sleep medication; and (PS7) daytime dysfunction. The total score is determined by the sum of the 7 component scores. Each component is scored from 0 to 3 . The global score (TS) ranges from 0 to 21 ( $\leq 5$ : good sleep quality; $>5$ : poor sleep quality; $\geq 15$ : important sleep impairment. Smokers were categorized according to the Pittsburgh Sleep Quality Index as poor and normal sleepers ${ }^{9,10}$.

Daytime sleepiness was evaluated with The Epworth Sleepiness Scale (ESS). It consists of 8 items that are each rated on a 4-point scale. ESS $<10$ corresponds to the absence of sleepiness, ESS 11-15 suggests excessive daytime sleepiness, and ESS $>6$ indicates severe sleepiness ${ }^{11}$.

We used the Beck Depression Inventory (BDI) to evaluate depressive symptoms. The BDI consists of 21 items rated on a 4-point scale. BDI<9 indicates absence of depression or minimal depressive symptoms, 10-18 indicates slight-to-moderate depression, 19-29 indicates moderate-to-severe depression, and 30-63 indicates severe depression ${ }^{12}$.

The Beck Anxiety Inventory (BAI) measures the intensity of anxiety symptoms. This questionnaire consists of 21 items that reflect typical somatic, emotional, and cognitive anxiety symptoms, rated on a 4-point scale from 0 to 3 . The total score may vary from 0 to 63 . $\mathrm{BAI}<10$ indicates the absence of anxiety or minimal anxiety symptoms, 11-19 indicates slight-to-moderate anxiety, 20-30 indicates moderate-tosevere anxiety, and 31-63 indicates severe anxiety ${ }^{13}$.

A generic questionnaire for the assessment of QoL (SF36) was used in this study. The SF-36 is composed of 36 items that measure eight health-related QoL domains; physical functioning $(\mathrm{PF})$, social functioning $(\mathrm{SF})$, role limitation due to physical problems (RP), role limitation due to emotional problems (RE), mental health $(\mathrm{MH})$, energy and vitality (VT), bodily pain (BP), and general perception of health $(\mathrm{GH})$. For each QoL domain tested, item scores were coded, summed, and transformed into a scale from 0 (worst) to 100 (best) using the standard SF-36 scoring algorithms. Besides that, Physical and Mental Summary Component Scale (PCS and MCS, respectively) scores were also calculated using the algorithm described by the developers ${ }^{14}$.

\section{Statistical analysis}

The data were analyzed using IBM SPSS Statistics $18^{\odot}$ SPSS Inc. Associations between categorical values were tested by calculating Chi-square and p values. Pearson correlation coefficients were calculated for the determination of correlations between continuous variables. Significant differences between groups for parametric continuous values were determined with Student's $t$-test while Mann-Whitney $\mathrm{U}$ tests were used for non-parametric continuous variables. The internal reliability of questionnaires was tested by calculating Cronbach's Alpha. The individual effects of separate questionnaire items were analyzed using ordinal logistic regression. A p <0.05 was considered significant. 


\section{RESULTS}

\section{Study population}

There were no differences between the groups in terms of age, sex, BMI, alcohol use, education period, work status, and Carlson comorbidity index. The demographic variables are shown in Table 1.

Although smokers tended to get out of bed at different times from day to day and do important work before bedtime more often than non-smokers no significant differences were detected between study groups for SHI total score (27.91 \pm 6.72 for smokers and $29.23 \pm 8.0$ for non-smokers) and each of the components (Table 2).

None of the components as well as the total score of PSQI were significantly different between smokers and nonsmokers (Table 3).

In addition, ESS score, depression and anxiety, mental and physical components, and all domains of QoL parameters did not differ significantly between smokers and nonsmokers (Table 3).

\section{Assessments in smokers}

Poor sleep was detected in 74 smokers $(65.5 \%)$. Thirtyfive out of 59 females (59\%) and 39 out of 55 males (70\%) had poor sleep quality according to the PSQI. We did not observe significant differences between poor and normal sleepers for BMI, gender, alcohol consumption, education, and comorbidities. The Fagerstrom score (mean $\pm \mathrm{SD}$ ) for smokers was
$4.30 \pm 2.97$ and the amount of pack/year was $17.78 \pm 4.30$ while the number of cigarettes smoked daily was 18.27. Fagerstrom nicotine addiction scores did not differ among smokers when they were categorized according to their PSQI status. Also, there was no correlation between pack/year and number of cigarettes smoked daily with sleep quality. There were no associations between Fagerstrom and total SHI scores as well as SHI components. Patients were categorized according to the Fagerstrom nicotine addiction level as high and low dependence, and no significant differences were found in SHI, PSQI scores, and QoL parameters.

Table 2. Sleep hygiene index results in study groups.

\begin{tabular}{lccc}
\hline & $\begin{array}{c}\text { Smokers } \\
(n=114)\end{array}$ & $\begin{array}{c}\text { Nonsmokers } \\
(n=119)\end{array}$ & p-value* \\
\hline Age & $37.34 \pm 11.30$ & $34.86 \pm 9.00$ & 0.063 \\
Sex & 58 & 76 & 0.08 \\
Female & 55 & 44 & \\
Male & $25.27 \pm 4.2$ & $24.34 \pm 3.8$ & 0.085 \\
Body mass index & 19 & & \\
Alcohol consumption & & 44 & \\
Consumer & 94 & 76 & \\
Non-consumer & $14.07 \pm 2.10$ & $13.60 \pm 3.40$ & 0.497 \\
\hline Education (years) & & & \\
\hline
\end{tabular}

*Student's t-test or chi-square test; $p<0.05$ was considered significant.

Table 1. Demographic variables of subjects.

\begin{tabular}{|c|c|c|c|}
\hline $\mathrm{SHI}$ & $\begin{array}{l}\text { Smokers } \\
(n=114)\end{array}$ & $\begin{array}{l}\text { Nonsmokers } \\
(n=119)\end{array}$ & $p$-value* \\
\hline Total & $27.92 \pm 6.69$ & $29.23 \pm 8.01$ & 0.177 \\
\hline 1. I take daytime naps lasting two or more hours. & $1.93 \pm 0.99$ & $1.96 \pm 0.91$ & 0.825 \\
\hline 2. I go to bed at different times from day to day & $3.01 \pm 1.32$ & $3.13 \pm 1.30$ & 0.466 \\
\hline 3. I get out of bed at different times from day to day. & $2.50 \pm 1.24$ & $2.79 \pm 1.25$ & 0.070 \\
\hline 4. I exercise within $1 \mathrm{~h}$ of going to bed & $1.17 \pm 0.46$ & $1.26 \pm 0.66$ & 0.263 \\
\hline 5. I stay in bed longer than I should two or three times a week. & $2.17 \pm 1.11$ & $2.27 \pm 1.16$ & 0.495 \\
\hline 6. I use alcohol, tobacco, or caffeine within $4 \mathrm{~h}$ of going to bed or after going to bed. & $2.56 \pm 1.66$ & $2.52 \pm 1.59$ & 0.881 \\
\hline $\begin{array}{l}\text { 7.I do something that may wake me up before bedtime (for example: play video } \\
\text { games, use the internet, or clean }\end{array}$ & $2.64 \pm 1.44$ & $2.78 \pm 1.54$ & 0.501 \\
\hline 8. I go to bed feeling stressed, angry, upset, or nervous. & $2.04 \pm 1.06$ & $2.03 \pm 1.13$ & 0.944 \\
\hline $\begin{array}{l}\text { 9. I use my bed for things other than sleeping or sex (for example: watch television, } \\
\text { read, eat, or study). }\end{array}$ & $2.27 \pm 1.45$ & $2.48 \pm 1.51$ & 0.268 \\
\hline $\begin{array}{l}\text { 10. I sleep on an uncomfortable bed (for example poor mattress or pillow, too much } \\
\text { or not enough blankets). }\end{array}$ & $1.39 \pm 0.73$ & $1.41 \pm 0.82$ & 0.869 \\
\hline $\begin{array}{l}\text { 11. I sleep in an uncomfortable bedroom (for example: too bright, too stuffy, too hot, } \\
\text { too cold, or too noisy }\end{array}$ & $1.30 \pm 0.69$ & $1.47 \pm 1.02$ & 0.136 \\
\hline 12. I do important work before bedtime (for example pay bills, schedule, or study) & $1.89 \pm 1.10$ & $2.15 \pm 1.22$ & 0.084 \\
\hline 13. I think, plan, or worry when I am in bed & $3.01 \pm 1.35$ & $3.08 \pm 1.36$ & 0.709 \\
\hline
\end{tabular}

SHI: Sleep Hygiene Index. Data are expressed as mean \pm SD or median (range). *Student $t$-test or chi-square test. 
Table 3. Epworth Sleepiness Scale and Pittsburg Sleep Quality Index results in study groups.

\begin{tabular}{|c|c|c|c|}
\hline & $\begin{array}{l}\text { Smokers } \\
(n=114)\end{array}$ & $\begin{array}{c}\text { Nonsmokers } \\
\quad(n=119)\end{array}$ & $p$-value* \\
\hline \multicolumn{3}{|c|}{ Epworth Sleepiness Scale } & \multirow[t]{3}{*}{0.331} \\
\hline$E S S<10$ & $94 ; 82.5 \%$ & $91 ; 76.5 \%$ & \\
\hline$E S S>10$ & $20 ; 17.5 \%$ & $28 ; 23.5 \%$ & \\
\hline Total & $7.19 \pm 3.92$ & $7.39 \pm 4.01$ & 0.331 \\
\hline \multicolumn{3}{|l|}{$\begin{array}{l}\text { Pittsburg Sleep } \\
\text { Quality Index }\end{array}$} & \multirow[t]{3}{*}{0.786} \\
\hline $\begin{array}{l}\text { TS }<5 \text { Good Sleep } \\
\text { Quality }\end{array}$ & $40 ; 35.1 \%$ & $44 ; 37 \%$ & \\
\hline $\begin{array}{l}\text { TS } \geq 5 \text { Poor Sleep } \\
\text { Quality }\end{array}$ & $74 ; 64.9 \%$ & $75 ; 63 \%$ & \\
\hline TS Total Score & $6.06 \pm 3.22$ & $6.28 \pm 3.53$ & 0.614 \\
\hline $\begin{array}{l}\text { PS1 Subjective } \\
\text { sleep quality }\end{array}$ & $1.25 \pm 0.76$ & $1.28 \pm 0.72$ & 0.748 \\
\hline PS2 Sleep latency & $1.28 \pm 1.12$ & $1.39 \pm 1.05$ & 0.424 \\
\hline PS3 Sleep duration & $0.94 \pm 0.89$ & $0.91 \pm 0.88$ & 0.788 \\
\hline PS4 Sleep efficiency & $0.29 \pm 0.65$ & $0.35 \pm 0.73$ & 0.548 \\
\hline $\begin{array}{l}\text { PS5 Sleep } \\
\text { disturbances }\end{array}$ & $1.25 \pm 0.54$ & $1.18 \pm 0.59$ & 0.355 \\
\hline $\begin{array}{l}\text { PS6 Use of sleep } \\
\text { medication }\end{array}$ & $0.08 \pm 0.41$ & $0.16 \pm 0.55$ & 0.262 \\
\hline $\begin{array}{l}\text { PS7 Daytime } \\
\text { dysfunction }\end{array}$ & $0.98 \pm 1.11$ & $0.93 \pm 1.01$ & 0.750 \\
\hline
\end{tabular}

ESS: Epworth Sleepiness Scale; PSQI: Pittsburgh Sleep Quality Index; TS: total score of Pittsburg; Student's $t$-test or chi-square test; $p<0.05$ was considered significant.

SHI scores were significantly associated with poor sleep quality and had a weak positive correlation with ESS ( $\mathrm{r}: 0.244$, $\mathrm{p}=0.00017$ ). Ordinal regression analysis showed that none of the individual items of the SHI showed a separate prominent effect on PSQI. There was a positive correlation between total SHI scores and both depression and anxiety indexes. Besides that, the total SHI score was negatively correlated with QoL parameters (Table 4).

Sleep quality correlated positively with depression and anxiety scores, while it correlated inversely with QoL (Table 5).

\section{DISCUSSION}

In our study, no significant differences were detected between smokers and nonsmokers for SHI total score and each of the components. SHI did not show any association with PSQI and ESS in smokers. Our results indicate that quality of life was impaired in smokers with poor sleep quality. Furthermore, impairment in quality of life was correlated with poor sleep quality and bad sleep hygiene.
Table 4. Correlation of Sleep Hygiene Index with depression and anxiety indexes and quality of life components in smokers.

\begin{tabular}{lcc}
\hline & Correlation coefficient & p-value \\
\hline Beck depression & 0.323 & $>0.001$ \\
Beck anxiety & 0.323 & $>0.001$ \\
\hline Physical functioning & -0.138 & 0.035 \\
\hline Pain & -0.185 & 0.005 \\
\hline General health & -0.171 & 0.009 \\
Vitality & -0.262 & $>0.001$ \\
\hline Social functioning & -0.228 & $>0.001$ \\
Emotional role & -0.198 & 0.002 \\
\hline General health & -0.267 & $>0.001$ \\
\hline Health change & -0.144 & 0.028 \\
\hline
\end{tabular}

Relationship between variables was evaluated with Pearson correlation. $p<0.05$ was considered significant.

Table 5. Correlation of Pittsburgh Sleep Quality Index with quality of life components in smokers.

\begin{tabular}{lcc}
\hline & Correlation coefficient & $p$-value \\
\hline Mental health & -0.381 & $>0.00001$ \\
Emotional role & -0.202 & 0.031 \\
\hline Social functioning & -0.369 & $>0.00001$ \\
\hline Vitality & -0.348 & $>0.00001$ \\
General health & -0.272 & 0.003 \\
\hline Pain & -0391 & $>0.00001$ \\
\hline Beck anxiety & 0.350 & $>0.00001$ \\
Beck depression & 0.325 & $>0.00001$ \\
\hline
\end{tabular}

Relationship between variables was evaluated with Pearson correlation. PSQI: Pittsburgh Sleep Quality Index; QoL: quality of life. $p<0.05$ was considered significant.

Smoking is the most common substance addiction in the community. In previous studies, sleep problems such as difficulty falling asleep, staying asleep, and daytime sleepiness were found to be more common in smokers than in non-smokers. These sleep disturbances can affect psychological and physiological functions and increase morbidity and mortality caused by smoking ${ }^{1,2,3}$. Smoking has a potentially stimulant effect due to nicotine. Therefore, smoking makes it difficult to fall asleep especially before bedtime, and negatively affects the quality of sleep. Nicotine promotes arousal and alertness through stimulation of cholinergic neurons in the basal forebrain ${ }^{15}$. Jaehne et al. demonstrated that nicotine, whether from cigarette smoking or administration via pill or patch, is associated with impaired sleep, increased sleep onset latency, decreased total sleep time, more frequent early morning awakening, and suppression of rapid eye movement (REM) sleep and slow-wave sleep $^{16}$. Moreover, not only consumption but also nicotine withdrawal would be associated with sleep disturbances 
leading to increased arousal ${ }^{17}$. Although there are controversial results in the literature, smoking has been linked to impaired sleep quality in many studies ${ }^{2,18}$. Our results indicate a higher rate of poor sleep quality in smokers, but smoking is not associated with worsened sleep quality or daytime sleepiness.

Sleep hygiene is defined as behaviors that facilitate sleep and avoidance of behaviors that have a negative effect on sleep. Poor sleep hygiene generally causes impairment in daily living activities due to a decrease in sleep quality and lack of daytime alertness. Sleep hygiene education can be a key strategy for improving sleep. Future research has the potential to expand sleep hygiene utility and evaluate its effectiveness ${ }^{8,19}$. Although studies emphasizing the importance of sleep hygiene have increased recently, there are few studies evaluating sleep hygiene in specific groups.

Smoking can have a serious effect on sleep hygiene both through direct effects of stimulants such as nicotine and caffeine on sleep and through indirect effects such as the disruption of sleep hygiene by smoking and the delay of bedtime. Therefore, avoiding nicotine use to improve sleep seems reasonable. However, if a nicotine-dependent individual is encouraged to quit smoking to get better sleep, the negative effects of nicotine withdrawal on sleep should not be ignored ${ }^{19}$. As far as we know, there is no study showing the relationship between smoking and sleep hygiene.

Besides that, the effect of sleep hygiene on sleep quality and quality of life of smokers has not been shown previously. In the present study, smoking was not associated with sleep hygiene behaviors assessed by a validated questionnaire. It seems that smoking per se has no effect on sleep hygiene, or these results come from questionnaires that included stimulant substances such as cigarettes and tea or coffee in the same query. In a country where the habit of drinking tea/ coffee at night is very strong, the effect of smoking on the same parameter could be masked or underestimated, and deterioration in sleep hygiene may not be detected with the standardized questionnaire. Other scales such as the Sleep Awake and Practice Scale (SHAP) ${ }^{20}$ or the Sleep Hygiene Self Test (SHST) ${ }^{21}$ can discriminate the effect of nicotine in separate questions. However, the SHI is the only validated questionnaire developed on the basis of diagnostic criteria for inadequate sleep hygiene described in the International Classification of Sleep Disorders. In fact, we found that poor sleep hygiene was correlated with poor sleep quality in smokers, similar to previous studies ${ }^{8,22,23}$. We showed the potential effect of poor sleep hygiene on sleep quality in a small population of smokers. Therefore, we concluded that more detailed validated tests are needed to evaluate sleep hygiene in smokers.

The relationship between nicotine addiction and/or the number of cigarettes smoked daily with sleep quality has been evaluated in previous studies. Palmer et al. found decreased mean sleep time in heavy smokers ${ }^{24}$. Cohrs et al. found that a higher degree of nicotine addiction and number of cigarettes smoked per day were associated with difficulty falling asleep and short sleep duration. In addition, as the number of pack-years increased, sleep duration was shortened and sleep disturbances increased, but its effect on sleep hygiene is unknown ${ }^{25,26}$. Indeed, we found no relationship between nicotine addiction and the number of cigarettes smoked daily with sleep hygiene as well as sleep quality.

It has been shown that smoking negatively affects many parameters of quality of life ${ }^{27,28}$. In limited data from Japanese studies, no difference was detected in quality of life scores between smokers and non-smokers. They argued that smokers in Japan may be less sensitive to sub-clinical deterioration of their health status than smokers in Western countries ${ }^{29,30,31}$. More comprehensive studies including different cohorts are needed to clarify associations between smoking and QoL, for which no data are available in the Turkish population so far. In our study, no statistically significant difference was found in QoL parameters between smokers and non-smokers. Smoking by itself was not associated with worse QoL in the Turkish population. To the best of our knowledge, there is no study in the literature showing the relationship between QoL and sleep hygiene in smokers. Furthermore, we showed an association between quality of life and sleep hygiene parameters in smokers with poor sleep quality. It can be concluded that sleep hygiene would be an important target for smokers with poor sleep quality.

Our study has some limitations. First, questionnaires evaluating sleep quality are self-reported. The gold standard diagnostic method for sleep disorder is polysomnography and sleep quality can be evaluated through interviews but neither method could not be used because of costs ${ }^{32,33}$. However, participants who have sleep disorders such as obstructive sleep apnea syndrome and restless leg syndrome were evaluated clinically using questionnaires developed for these disorders and excluded from the study. As another limitation, the fact that other stimuli such as nicotine, tea, and coffee were not used as separate parameters in our validated questionnaire may affect our results.

To the best of our knowledge, there is no study of the effects of smoking on sleep hygiene. Although our data have shown that smoking has no specific effect on sleep hygiene and sleep quality, further prospective studies with objective tests are needed because of the observed negative effects of nicotine on sleep architecture.

\section{ACKNOWLEDGMENT}

We acknowledge Ozan Tiryakioglu, who passed away while preparing the article, for statistical analysis. 
1. Phillips BA, Danner FJ. Cigarette smoking and sleep disturbance. Arch Intern Med. 1995 Apr;155(7):734-7.

2. Zhang L, Samet J, Caffo B, Punjabi NM. Cigarette smoking and nocturnal sleep architecture. Am J Epidemiol. 2006 Sep;164(6):52937. https://doi.org/10.1093/aje/kwj231

3. Centers for Disease Control. Cigarette smoking among adultsUnited States, 2000. MMWR. 2002 Jul;51(29):642-5.

4. Wetter DW, Young TB. The relation between cigarette smoking and sleep disturbance. Prev Med. 1994 May;23(3):328-34. https://doi. org/10.1006/pmed.1994.1046

5. Stepanski EJ, Wyatt JK. Use of sleep hygiene in the treatment of insomnia. Sleep Med Rev. 2003 Jun;7(3):215-25. https://doi. org/10.1053/smrv.2001.0246

6. Ebbert JO, Patten CA, Schroeder DR. The Fagerström Test for Nicotine Dependence-Smokeless Tobacco (FTND-ST). Addict Behav. 2006 Sep;31(9):1716-21. https://doi.org/10.1016/j.addbeh.2005.12.015

7. Mastin DF, Bryson J, Corwyn R. Assessment of sleep hygiene using the Sleep Hygiene Index. J Behav Med. 2006 Jun;29(3):223-7. https:// doi.org/10.1007/s10865-006-9047-6

8. Ozdemir PG, Boysan M, Selvi Y, Yildirim A, Yilmaz E. Psychometric properties of the Turkish version of the Sleep Hygiene Index in clinical and non-clinical samples. Compr Psychiatry. 2015 May;59:135-40. https://doi.org/10.1016/j.comppsych.2015.02.001

9. Buysse DJ, Reynolds III CF, Monk TH, Berman SR, Kupfer DJ. The Pittsburgh Sleep Quality Index: a new instrument for psychiatric practice and research. Psychiatry Res. 1989 May;28(2):193-213. https://doi.org/10.1016/0165-1781(89)90047-4

10. Ağargün MY, Kara H, Anlar O. Pittsburgh uyku kalitesi indeksinin geçerliği ve güvenirliği. Türk Psikiyatri Dergisi. 1996;7.2:107-15.

11. Johns MW. Reliability and factor analysis of the Epworth Sleepiness Scale. Sleep. 1992 Aug;15(4):376-81. https://doi.org/10.1093/ sleep/15.4.376

12. Beck AT, Steer RA, Carbin MG. Psychometric properties of the Beck Depression Inventory: Twenty-five years of evaluation. Clin Psychol Rev. 1993;8(1):77-100. https://doi.org/10.1016/0272-7358(88)90050-5

13. Beck AT, Steer RA. Beck Anxiety Inventory: BAI. Psychological Corporation. San Antonio, TX; 1993.

14. Ware JE, Snow KK, Kosinski M, Gandek B. SF-36 - Health Survey: manual and interpretation guide. Boston: Health Institute; 1993

15. Boutrel B, Koob GF. What keeps us awake: the neuropharmacology of stimulants and wakefulness-promoting medications. Sleep. 2004 Sep;27(6):1181-94. https://doi.org/10.1093/sleep/27.6.1181

16. Jaehne A, Loessl B, Bárkai Z, Riemann D, Hornyak M. Effects of nicotine on sleep during consumption, withdrawal, and replacement therapy. Sleep Med Rev. 2009 Oct;13(5):363-77. https://doi. org/10.1016/j.smrv.2008.12.003

17. Colrain IM, Trinder J, Swan GE. The impact of smoking cessation on objective and subjective markers of sleep: review, synthesis, and recommendations. Nicotine Tob Res. 2004 Dec;6(6):913-25. https:// doi.org/10.1080/14622200412331324938

18. Haseli-Mashhadi N, Dadd T, Pan A, Yu Z, Lin X, Franco OH. Sleep quality in middle-aged and elderly Chinese: distribution, associated factors, and associations with cardio-metabolic risk factors. BMC Public Health. 2009 May;9:130. https://doi.org/10.1186/1471-2458-9-130
19. Irish LA, Kline CE, Gunn HE, Buysse DJ, Hall MH. The role of sleep hygiene in promoting public health: A review of empirical evidence. Sleep Med Rev. 2015 Aug;22:23-36. https://doi.org/10.1016/j. smrv.2014.10.001

20. Lacks P, Rotert M. Knowledge, and practice of sleep hygiene techniques in insomniacs and good sleepers. Behav Res Ther. 1986;24(3):365-8. https://doi.org/10.1016/0005-7967(86)90197-x

21. Blake DD, Gómez MH. A scale for assessing sleep hygiene: preliminary data. Psychol Rep. 1998 Dec;83(3 Pt 2):1175-8. https:// doi.org/10.2466/pr0.1998.83.3f.1175

22. Brick CA, Seely DL, Palermo TM. Association between sleep hygiene and sleep quality in medical students. Behav Sleep Med. 2010;8(2):113-21. https://doi.org/10.1080/15402001003622925

23. Lee SA, Han SH, No YJ, Jo KD, Kwon JH, Kim JY, et al. Sleep hygiene and its association with mood and quality of life in people with epilepsy. Epilepsy Behav. 2015 Nov;52(Pt A):225-9. https://doi. org/10.1016/j.yebeh.2015.09.011

24. Palmer CD, Harrison GA, Hiorns RW. Association between smoking and drinking and sleep duration. Ann Hum Biol. Mar-Apr 1980;7(2):103-7. https://doi.org/10.1080/03014468000004111

25. Cohrs S, Rodenbeck A, Riemann D, Szagun B, Jaehne A, Brinkmeyer $J$, et al. Impaired sleep quality and sleep duration in smokers-results from the German Multicenter Study on Nicotine Dependence. Addict Biol. 2014 May;19(3):486-96. https://doi.org/10.1111/j.13691600.2012.00487.x

26. Riedel BW, Durrence HH, Lichstein KL, Taylor DJ, Bush AJ. The relation between smoking and sleep: the influence of smoking level, health, and psychological variables. Behav Sleep Med. 2004;2(1):6378. https://doi.org/10.1207/s15402010bsm0201_6

27. Goldenberg M, Danovitch I, IsHak WW. Quality of life and smoking. Am J Addict. 2014 Nov-Dec;23(6):540-62. https://doi.org/10.1111/j.15210391.2014.12148.x

28. Nduaguba SO, Ford KH, Rascati K. The role of physical activity in the association between smoking status and quality of life. Nicotine Tob Res. 2019 Jul;21(8):1065-71. https://doi.org/10.1093/ntr/nty052

29. Funahashi K, Takahashi I, Danjo K, Matsuzaka M, Umeda T, Nakaji S. Smoking habits and health-related quality of life in a rural Japanese population. Qual Life Res. 2011 Mar;20(2):199-204. https://doi. org/10.1007/s11136-010-9748-8

30. Kimura T, Ogushi Y, Takahashi M, Munakata Y, Ishii S. Association of health-related quality of life with health examination including organic functions and lifestyles in Japanese employees. Qual Life Res. 2004 Mar;13(2):519-29. https://doi.org/10.1023/ B:QURE.0000018480.11690.79

31. Kimura T, Ogushi Y, Haruki Y, Okada Y. Is interest in art effective in health-related quality of life? Results of a cross-sectional survey on lifestyle and health promotion. Tokai J Exp Clin Med. 2000 Oct;25(3):141-9.

32. Jaehne A, Unbehaun T, Feige B, Lutz UC, Batra A, Riemann D. How smoking affects sleep: a polysomnographical analysis. Sleep Med. 2012 Dec;13(10):1286-92. https://doi.org/10.1016/j.sleep.2012.06.026

33. Cohen A, Ben Abu N, Haimov I. The interplay between tobacco dependence and sleep quality among young adults. Behav Sleep Med. 2020 Mar-Apr;18(2):163-76. https://doi.org/10.1080/15402002. 2018.1546707 